\title{
Reconstituição paleoclimática do vale do Rio Caí, nordeste do Rio Grande do Sul, com ênfase nas ocupações humanas
}

\author{
Walter Mareschi Bissa* \\ Adriana Schmidt Dias** \\ Eduardo Luis Martins Catharino***
}

\begin{abstract}
BISSA, W.M.; DIAS, A.S.; CATHARINO, E.L.M. Reconstituição paleoclimática do vale do Rio Caí, nordeste do Rio Grande do Sul, com ênfase nas ocupações humanas. Revista do Museu de Arqueologia e Etnologia, São Paulo, 19: 143-154, 2009.
\end{abstract}

Resumo: A análise palinológica do perfil sedimentar de uma várzea do vale do Rio Caí, nordeste do estado do Rio Grande do Sul (Brasil), mostrou mudanças nas condições ambientais. As amostras foram tratadas com HCL, $\mathrm{KOH}, \mathrm{HF}$ e acetólise. Para cada amostra foi contado um número mínimo de 300 grãos de pólen. Os resultados indicam que há ca. 1260 anos AP a região era ocupada por vegetação campestre e clima seco, havendo posteriormente um aumento de áreas florestais ( 1000 a 600 anos AP), com queimadas provocadas, muito provavelmente, por ação antrópica. A partir de 600 anos AP até o presente ocorreu aumento de umidade e temperatura, com clima próximo ao atual. Os dados paleoambientais sugerem que tanto as áreas campestres como as áreas florestais adaptaram-se às demandas para a obtenção de recursos sazonais das populações pré-coloniais que ocuparam a região.

Palavras-chave: Palinologia - Paleoambiente - Holoceno - Ocupação précolonial do vale do Rio Caí (RS).

\section{Introdução}

$\square$ studos paleoclimáticos e paleoambientais realizados recentemente nas regiões

$\left.{ }^{*}\right)$ Museu de Arqueologia e Etnologia da Universidade de São Paulo.<walbissa@usp.br>

$\left.{ }^{* *}\right)$ Departamento de História e Programa em História do Instituto de Filosofia e Ciências Humanas da Universidade Federal do Rio Grande do Sul. Bolsista Produtividade em Pesquisa CNPq.<dias.a@uol.com.br>

$\left.{ }^{* * *}\right)$ Pesquisador Científico VI do Instituto de Botânica de São Paulo (IBt).<mcatarin@uol.com.br> sul e sudeste do Brasil têm indicado que o início do processo de formação e expansão das florestas subtropicais teria se iniciado na transição Pleistoceno-Holoceno (Ledru et al. 1996, 1998; Behling 1997, 2002; Behling e Lichte 1997; Behling e Negrelle 2001; Behling et al. 2001, 2004; Grala \& Lorsheitter 2001; Araujo et al. 2005; Bauermann 2003). De acordo com Araujo e colaboradores (2005), os estudos palinológicos desenvolvidos nos últimos anos para os Estados do Paraná, Santa Catarina e Rio Grande do Sul apontam uma melhora constante das condições climáticas ao 
longo do Holoceno. Embora o último Máximo Glacial e o Último Glacial tenham apresentado um clima extremamente seco e frio, com expansão de pradarias onde hoje ocorre uma variedade de ecossistemas florestais, durante o Holoceno houve uma tendência bastante recuada para o aumento da pluviosidade na área costeira. Isto ocorreu, provavelmente, em função de fatores orográficos, havendo indícios da presença de uma incipiente floresta chuvosa já ao redor de 12300 anos AP. Com base nestes dados, os autores sugerem que a ocupação humana do sul do Brasil parece não ter sofrido restrições em função da umidade, temperatura e sazonalidade de recursos, apresentando-se estável frente a um clima mais moderado se comparado com o Brasil Central (em relação à disponibilidade de água - Salgado-Labouriau, 2001) e com o Pampa Argentino (em relação às baixas temperaturas e disponibilidade de água) (Araujo et al. 2005).

Esta tendência ambiental ao longo do Holoceno ofereceu condições favoráveis à atração e fixação populacional antiga no sul do Brasil, sugerindo os dados arqueológicos que as rotas iniciais de povoamento da região por caçadores coletores acompanharam o processo de evolução da paisagem florestal (Dias e Jacobus 2001; Dias 2003, 2004). Estas características ambientais também teriam desempenhado um papel central para a colonização Guarani da região sul brasileira, cujas datações mais antigas no estado do Rio Grande do Sul se dão por volta de 1800 anos AP para o vale do rio Jacuí (Dias 2009; Noelli 1999/2000).

No sentido de contribuir para o melhor entendimento destes processos, o presente trabalho enquadra-se no âmbito do projeto Reflexos da Dinâmica Ambiental Holocênica nas Estratégias de Adaptação de Caçadores Coletores da Região Nordeste do Rio Grande do Sul (10000 a 400 anos AP), implementado em 2005, sob coordenação de Adriana Schmidt Dias. Contando com apoio financeiro do $\mathrm{CNPq}\left(\mathrm{n}^{\circ}\right.$ processo 474630/04-8) e apoio institucional da UFRGS, seus objetivos visam obter dados a respeito dos paleoclimas e das variações ambientais ocorridas durante o Holoceno no vale do rio Caí, nordeste do Rio Grande do
Sul, para uma melhor avaliação da dinâmica de interação dos cenários paleoambientais com os processos de ocupação humana. A escolha desta região deve-se ao fato de se tratar de uma área na qual estudos arqueológicos sistemáticos vêm se desenvolvendo nos últimos 40 anos, evidenciando uma sequência de ocupações humanas ao longo de todo o Holoceno. Por sua vez, o processo de expansão da Floresta Estacional nesta região é atestado em 9800 anos AP apenas por um estudo palinológico preliminar de uma turfeira no município de Montenegro (Grala e Lorscheitter 2001) o que torna pertinente a análise aqui apresentada.

\section{Área de estudo}

A bacia hidrográfica do rio Caí localiza-se no Rio Grande do Sul, integrando a bacia do Lago Guaíba. Abrangendo uma área de 5.057,25 km², limita-se a sul e a leste com a bacia hidrográfica do rio dos Sinos e a norte com a bacia hidrográfica dos rios Taquari e Antas (Diesel 2005). O rio Caí, principal afluente desde suas nascentes mais altas, a $1000 \mathrm{~m}$ de altitude, até sua foz, no delta do Jacuí, percorre $257,6 \mathrm{~km}$. Sua origem é considerada a nascente do arroio São Jorge que deságua no rio Santa Cruz (FEPAM-GTZ, apud Diesel 2005).

A área de estudo aqui analisada localiza-se na região de Serra Velha, município de Tabaí, entre as coordenadas $51^{\circ} 39^{\prime} 17^{\prime \prime}$ W e $29^{\circ} 38^{\prime} 32^{\prime \prime} \mathrm{S}$, próxima à localidade do Morro dos Rodrigues (Fig. 1). Compreende o alto curso dos vales dos arroios Maratá e Brochier, afluentes da margem direita do rio Caí, abrangendo os territórios municipais de Brochier e Maratá.

A geomorfologia da região é caracterizada pelos Patamares da Serra Geral, sendo aí representados por terminais rebaixados que avançam sobre a planície costeira, a leste, e sobre a Depressão Central Gaúcha, ao sul. Na Unidade Serra Geral, seu compartimento Aparados da Serra ocorre no sentido norte-sul, desde Santa Catarina (na altura de Criciúma) 

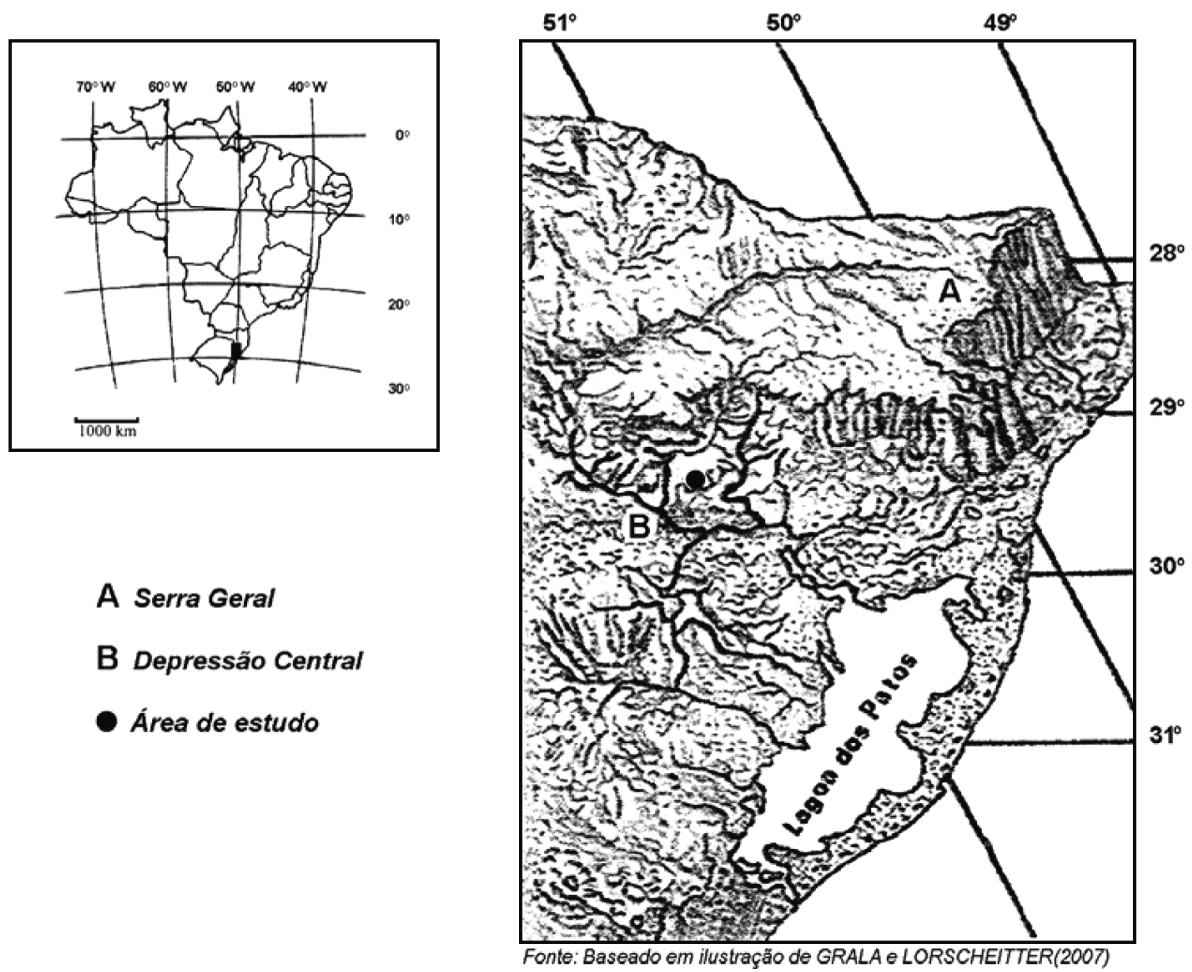

Fig. 1. Relevo do Rio Grande do Sul com a localização da área de estudo (Município de Tabai).

até a lagoa das Malvas, quando se direciona bruscamente para o oeste. A Área Serrana da Unidade Serra Geral inicia-se na altura da Lagoa das Malvas e tem um sentido leste-oeste. Nela ocorrem os altos vales dos rios Antas, Taquari, Caí e dos Sinos. Nas bacias dos rios Caí e Taquari ocorre o recuo das vertentes de seus vales, apresentando-se encaixados em meio a amplas áreas planas e entrando em contato com a Região da Depressão Central Gaúcha através de relevos abruptos (IBGE 1986).

O segmento inferior do rio Caí, em direção à foz, faz parte da Unidade Geomorfológica Planície Lagunar e da Unidade Geomorfológica Planície Aluvio-Coluvionar que constitui a Região Geomorfológica Planície Costeira Interna. O extremo inferior do rio Caí está incluído no delta do rio Jacuí, em contato com a Unidade Geomorfológica da Planície Lagunar (SEPLAN/IBGE 1986, apud Diesel 2005).

A região nordeste do Rio Grande do Sul é caracterizada por duas unidades geológicas distintas, quais sejam, a Formação Botucatu e a
Formação Serra Geral. A Formação Botucatu é constituída por arenitos eólicos, de granulação média à fina e estratificação cruzada, situados abaixo dos derrames basálticos da Formação Serra Geral. Os basaltos da Formação Serra Geral apresentam uma baixa cristalização, possuindo zonas de fratura ou diaclasamento descontínuo, em função da velocidade em que ocorreu seu resfriamento. As formações de arenito e basalto da borda do planalto meridional estão sujeitas à erosão devido à alta pluviosidade da região, facilitando seu arraste por ação fluvial (IBGE 1986; Grehs 1976; Rambo 1994).

Apresentando um clima subtropical sempre úmido, segundo a classificação de Köppen, esta área apresenta verões quentes (com média em torno de $20^{\circ} \mathrm{C}$ ) e invernos brandos (com máxima em torno de $15^{\circ} \mathrm{C}$ ). A média de precipitações anuais gira em torno de $1.500 \mathrm{~mm}$, distribuídos regularmente, estando a umidade relativa em torno de 75 a 85 \% e a insolação na casa dos 54\%. Em termos gerais, a região encontra-se na área de abrangência das Florestas 
Estacionais Deciduais, cujo extrato emergente perde suas folhas no inverno. Esta formação vegetal localiza-se no Rio Grande do Sul na maior parte da Serra Geral e patamares, no trecho que se situa desde sua extrema ocorrência a oeste, até o vale do rio Caí a leste. Recobre a Depressão Central gaúcha, logo ao sul da Serra Geral, estendendo-se pelas planícies e terraços aluviais do rio Jacuí e afluentes. No vale do rio Caí, encontramos uma divisão fito-fisionômica desta formação vegetal, denominada submontana, cujo limite na cota altimétrica encontra-se entre 300 e 400 metros, sendo nela encontradas 209 espécies arbóreas além de várias espécies de leguminosas e cactáceas, entre outras (IBGE 1986; Noelli 1993; Rambo 1994).

\section{O contexto arqueológico}

Pesquisas arqueológicas foram realizadas no vale do rio Caí e principais afluentes entre 1965 e 1989, através de trabalhos de campo coordenados pelos arqueólogos Pedro Ignácio Schmitz, Eurico Miller e Pedro Augusto Mentz Ribeiro. Estas atividades permitiram o registro de 111 sítios arqueológicos, encontrando-se o acervo derivado destas pesquisas sob a guarda do Museu Arqueológico do Rio Grande do Sul (MARSUL), do Centro de Ensino e Pesquisas Arqueológicas da Universidade de Santa Cruz do Sul (CEPA/UNISC) e do Instituto Anchietano de Pesquisas da Universidade do Vale do Rio dos Sinos (IAP/UNISINOS).

O levantamento realizado junto ao acervo dessas instituições e das publicações derivadas dessas pesquisas indica a presença ao longo do curso do rio Cai de 35 sítios em abrigo sob rocha. Quanto aos sítios a céu aberto, 46 são sítios cerâmicos ou lito-cerâmicos associados à Tradição Guarani e 17 estão relacionados à Tradição Taquara, dos quais 12 apresentam estruturas subterrâneas localizadas no alto curso do rio. Destaca-se ainda entre os sítios a céu aberto a ocorrência de 11 sítios líticos, dos quais seis estão associados à Tradição Umbu em função da presença de pontas de projétil. Nestas pesquisas foram ainda registrados dois sítios históricos relacionados à Tradição neobrasileira, sendo um destes em abrigo sob rocha (Dias 1994; Ribeiro 1972, 1974; Ribeiro et al. 1989; Ribeiro \& Ribeiro 1999; Schmitz 1985).

Em relação à ocupação caçadora-coletora, as pesquisas arqueológicas permitiram a localização de 37 sítios associados à Tradição Umbu, principalmente relacionados ao médio curso do rio. As 10 datações atualmente disponíveis para o vale do rio Caí apontam para uma sequência de ocupação contínua ao longo do Holoceno para grupos de caçadores coletores, sendo o mesmo padrão observado no vale do rio dos Sinos, distante aproximadamente $150 \mathrm{~km}$ e com 15 datações entre 8800 e 440 anos AP para contextos similares (Dias 2003). As datações para sítios da Tradição Umbu no vale do rio Caí distribuem-se entre 9430 e 630 anos AP, estando relacionadas aos seguintes sítios:

a) RS-C-14: Bom Jardim Velho que apresentou duas datações de $5655 \pm 140$ AP (SI-1199) e $745 \pm 115$ AP (SI-1198);

b) RS-C-12: Virador, com uma datação de $630 \pm 205$ AP (SI-1201);

c) RS-TQ-58: Garivaldino Rodrigues, com quatro datações de $9430 \pm 360$ AP (BA 44739), $8290 \pm 130$ AP (BA 32183), 8020 \pm 150 AP (BA 33458), $7250 \pm 350$ AP (BA 44740).

d) RS-C-61: Adelar Pilger, com três datações de $8010 \pm 50$ AP (Beta 229583), 6150 $\pm 50 \mathrm{AP}$ (Beta 227856) e 3000 40 AP (UGA 02017).

Para a ocupação de horticultores no vale do rio Caí, possuímos apenas uma datação radiocarbônica para o sítio da Tradição Guarani RS-C-63: Adolfo Schenkel, com valores de

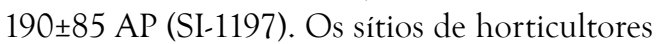
da Tradição Taquara apresentam datações relacionadas somente ao sítio RS-127: Antônio Vergani (sinonímia RS-37), situado no município de Caxias do Sul, alto vale do rio Caí. Este sítio apresenta um conjunto de 36 casas subterrâneas, tendo sido realizadas cinco datações radiocarbônicas com os seguintes valores: $1480 \pm 70 \mathrm{AP}$ (SI-603), $1330 \pm 100 \mathrm{AP}$ (SI-605), 1140 \pm 40 AP (SI-602), 840 \pm 60 AP (SI606), 630 \pm 70 AP (SI-604). 


\section{Material e métodos}

Foram coletadas quatro amostras de sedimento da superfície dos solos periféricos ao redor da várzea selecionada, que tem por finalidade fornecer os padrões atuais na deposição dos palinomorfos para auxiliarem na interpretação dos diagramas polínicos quaternários (Ybert et al. 1992).

O testemunho foi coletado na localidade de Serra Velha município de Tabaí entre as coordenadas 51'39'17" W e 29॰38'32" S (Fig.1) em uma várzea com um amostrador do tipo Hiller, que alcançou $120 \mathrm{~cm}$ de profundidade e é constituído por uma sequência de argila cinza escura. A superfície do sedimento foi limpa com uma espátula e seccionada em intervalos de $10 \mathrm{~cm}$ ao longo da sequência sedimentar que em seguida foram acondicionados em sacos plásticos etiquetados com os dados de profundidade.

O tratamento químico para a extração dos palinomorfos seguiu a técnica de Faegri \& Iversen (1989). A preparação do sedimento consiste das seguintes etapas:

1 - adição de duas pastilhas de Lycopodium clavatum em cada amostra;

2 - eliminação dos carbonatos com ácido clorídrico $(\mathrm{HCl})$ a $10 \%$. Lavagem com água destilada;

3 - eliminação do sedimento de maior granulometria por peneiração em malha de $250 \mu \mathrm{m}$. Lavagem com água destilada;

4 - eliminação dos ácidos húmicos com hidróxido de potássio $(\mathrm{KOH})$ a $10 \%$;

5 - eliminação de uma parte da matéria orgânica numa mistura de anidrido acético com ácido sulfúrico 9/1;

6- separação dos minerais pesados e da matéria orgânica (pólen e esporos) com HF a $40 \%$. Lavagem com água destilada;

7- recuperação do resíduo palinológico em pequenos tubos de plástico com algumas gotas de glicerina;

8- adição de uma pequena alíquota do resíduo polínico na lâmina com glicerina; lutagem com parafina.
Em cada amostra selecionada tanto da superfície, quanto dos sedimentos quaternários, foram identificados e contados no mínimo 300 grãos de pólen e esporos de pteridófitas e briófitas. Foram obtidas as concentrações dos palinomorfos baseando-se na contagem do número absoluto de grãos de pólen e esporos por unidade de volume analisada (Stockmarr 1971). Utilizando-se o software Tília e Tilia Graph (Grimm 1987) foram construídos diagramas palinológicos, estabelecendo-se as associações de palinomorfos importantes e as zonas bioestratigráficas. Estes diagramas mostram as variações das associações de palinomorfos nos diversos níveis estratigráficos. As variações na composição esporo-polínica de cada uma dessas zonas avaliaram as mudanças paleoambientais que ocorreram através do tempo representado pelos depósitos de sedimentação.

Uma amostra da camada basal $(120 \mathrm{~cm})$ com posicionamento estratigráfico controlado foi enviada para o Laboratório de Isotopos da University of Georgia, para fins de datação radiométrica. Esta amostra foi datada em $1260 \pm 40$ anos AP. A outra datação de 110 anos AP $(10 \mathrm{~cm})$ foi estimada baseando-se em Grala $\&$ Lorscheitter (2007).

\section{Resultados}

\section{Análises Palinológicas}

Os estudos palinológicos da sequência sedimentar da área de estudo contendo $120 \mathrm{~cm}$ de sedimentos, com idade basal de $1260 \pm 40$ anos AP, evidenciam mudanças climáticas e vegetacionais na área de estudo. Os diagramas palinológicos de porcentagem e concentração permitiram observar sete ecozonas, descritas a seguir.

Ecozona $1(120-110 \mathrm{~cm}-1260 \pm 40$

AP): poucos pólens e esporos, predomínio de campo de gramíneas (Fig. 2).

Clima é relativamente seco e mais continental.

Ecozona $2(110-90 \mathrm{~cm})$ : aumento de áreas de floresta, aumento da quantida- 
de de matéria orgânica (concentração total de palinomorfos - Fig. 3), vegetação mais diversificada. Aumento de precipitações pluviais e temperatura. Concentrações bastante altas de partículas de carvão (Fig. $3 \pm 1000$ anos AP - idade interpolada) sugerem queimadas muito provavelmente por ação antrópica.

Ecozona $3(90-70 \mathrm{~cm})$ : diminuição das concentrações de pólens e esporos, decréscimo de árvores e arbustos, poucas pteridófitas (Fig. 3). Clima mais seco e bem estacional (chuva num período e seca em outro) e um pouco mais quente, provavelmente a bacia de sedimentação secou muito e ocorreu redeposição dos sedimentos na superfície.

Ecozona $4(70-50 \mathrm{~cm})$ : aumento de umidade marcado por um pico de cyperaceas que inundou a várzea (a floresta quase que desaparece - Fig. 2). Baixa concentração de elementos arbóreos, sugerindo clima úmido e temperaturas mais baixas. Um pico de concentrações de partículas de carvões ( \pm 600 anos AP - idade interpolada) indica frequentes queimadas que muito provavelmente ocorreram devido à ação antrópica (Fig. 3).

Ecozona $5(50-30 \mathrm{~cm})$ : aumento de temperatura e clima mais próximo do atual (menor pluviosidade), a floresta volta a se estabelecer com expansão de áreas florestadas de mirtáceas (o que pode indicar a colonização da várzea por árvores/arbustos) (Fig. 2).

Ecozona $6(30-10 \mathrm{~cm})$ : ligeiro aumento de gramíneas/compositae, áreas florestadas (Fig. 3) sendo substituídas por campos ou vegetação mais aberta e com predomínio de Myrtaceae (Fig. 2). Aumento de Euphorbiaceae (indicativo de alteração ambiental). Concentrações elevadas de todos os palinomorfos (Fig. 3) podem indicar aumento de precipitações pluviométricas (entrada de influxos de água doce).

\section{Ecozona $7(10-0 \mathrm{~cm}-110 \pm 60 \mathrm{AP})$ :}

decréscimo de áreas florestadas, cobertura herbácea e diminuição notável de pteridófitas (várzea mais seca - Fig. 3). Provavelmente ocorreu o desenvolvimento de pastagem devido à ação antrópica.

\section{Discussão}

Os dados paleoambientais disponíveis para a região sul brasileira apontam para uma tendência à estabilização de um clima mais úmido e quente a partir de 12300 anos AP, associado à expansão da floresta subtropical. Por sua vez, estudos palinológicos realizados no nordeste do estado do Rio Grande do Sul indicam uma tendência ao desenvolvimento inicial da floresta estacional subtropical por volta de 9800 anos AP, apresentando contemporaneidade com o início da ocupação caçadora coletora na área (Araujo et al. 2005; Behling \& Negrelle 2001; Dias 2003; Grala \& Lorscheitter 2001; Stevaux 2000).

Os dados paleovegetacionais das ecozonas 1 e 2 (Fig. 3) sugerem que os ambientes de campo aberto (ecozona 1) e de áreas florestadas (ecozona 2) se adaptam perfeitamente às necessidades de mobilidade dos caçadores coletores da Tradição Umbu para obtenção de recursos sazonais nas diversas épocas do ano. Tomando por referência os estudos aqui apresentados, podemos sugerir que o sistema de mobilidade destes caçadores coletores seria influenciado pela presença concentrada de recursos sazonais, variando o número de deslocamentos e o tamanho dos territórios de forragem de acordo com as estações. Nos períodos de maior produtividade da flora (verão e primavera), os movimentos residenciais seriam mais restritos, havendo uma maior proximidade entre os acampamentos residenciais e uma maior permanência nos assentamentos. Durante o inverno, a diminuição na produtividade da flora determinaria uma maior distância entre as bases residenciais, uma menor permanência nos acampamentos e áreas de forragem mais extensas (Dias 1994, 2003, 2004, 2009). 


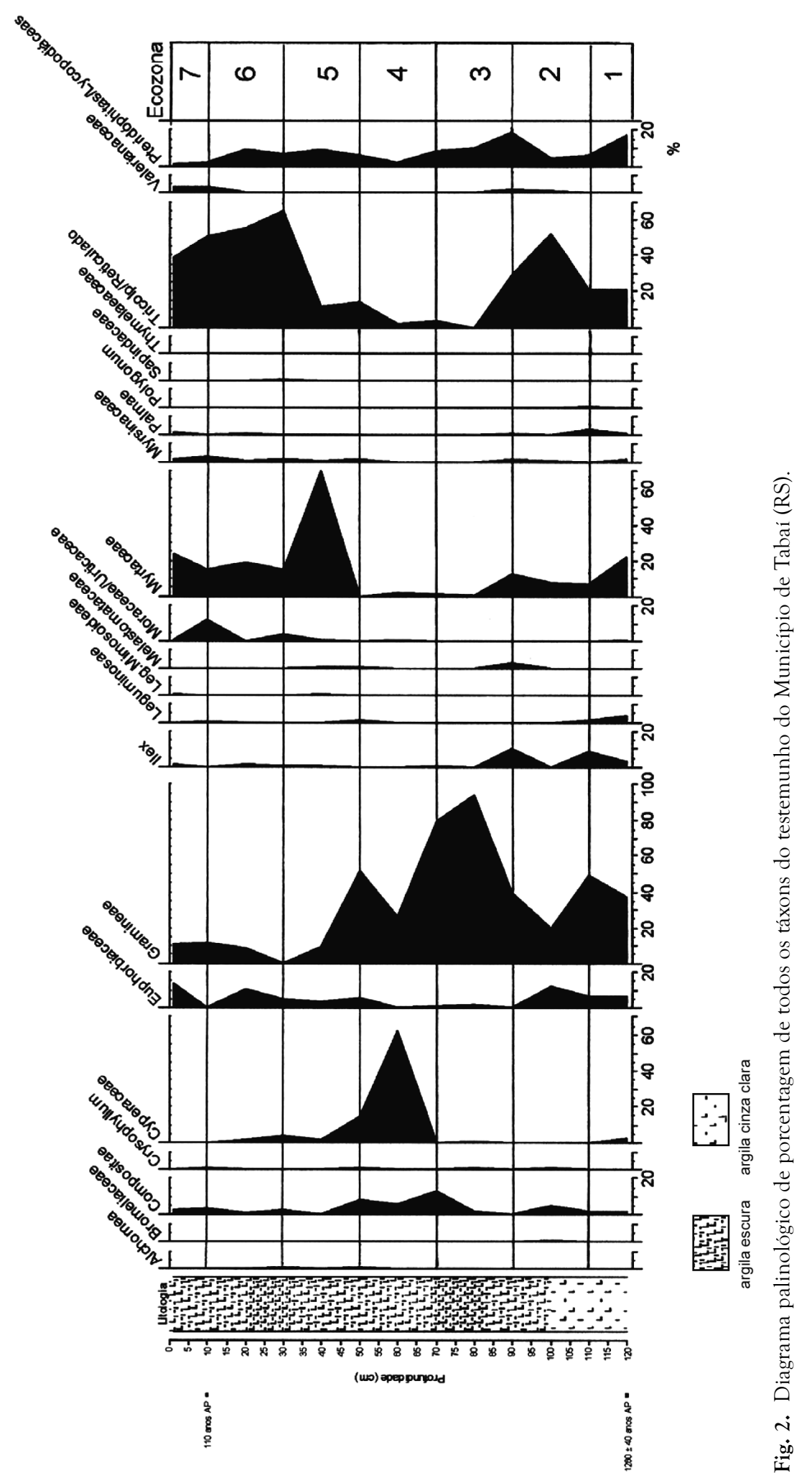




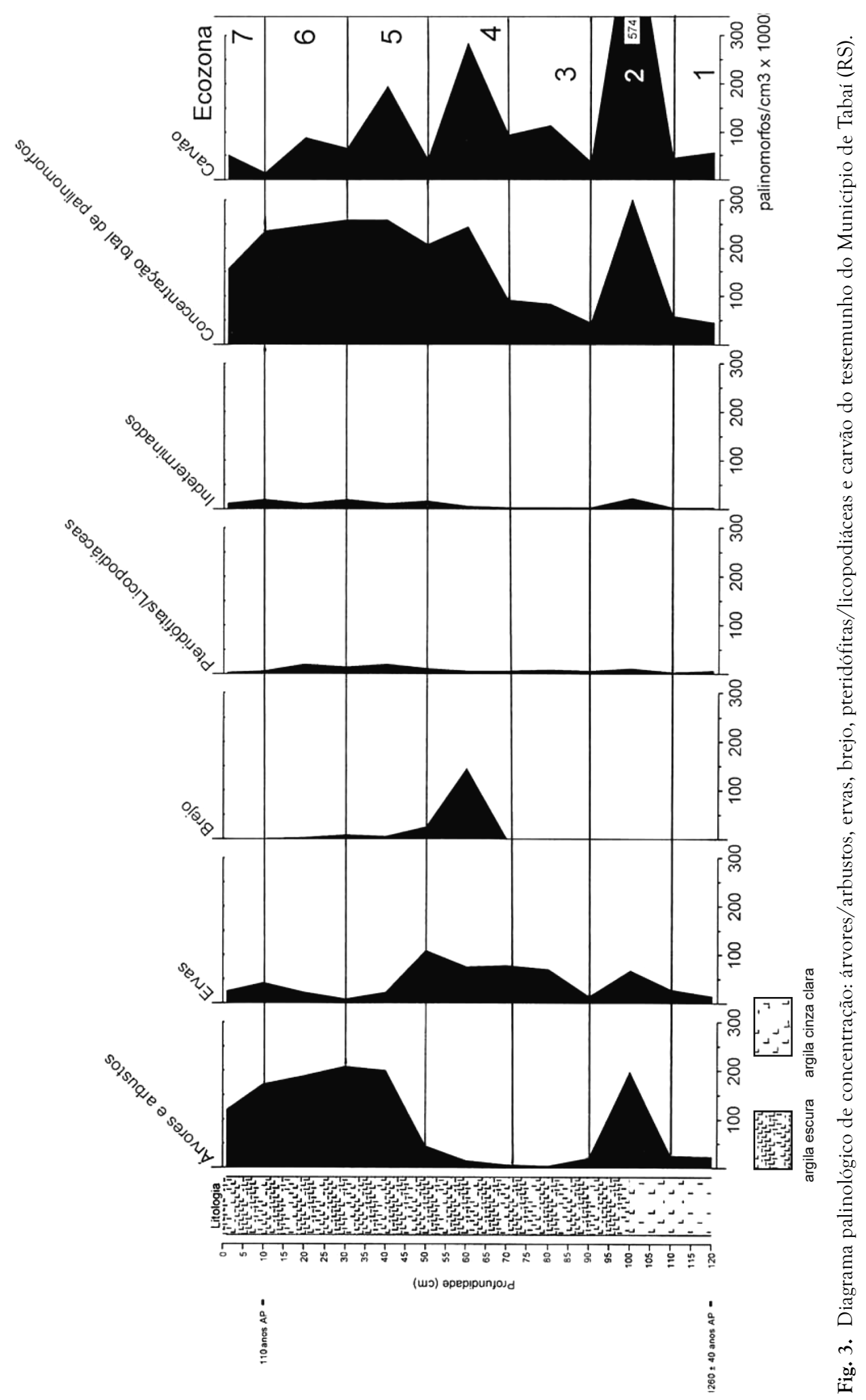


Neste cenário de considerável estabilidade ambiental, podemos sugerir que as populações de caçadores-coletores tenham tido uma longa convivência com os ambientes florestais desde pelo menos o Holoceno Médio. Esta perspectiva contraria, em parte, a visão tradicional de que estes grupos teriam preferência por ambientes mais abertos. De fato, tanto a cronologia como o repertório tecnológico destes grupos parecem indicar uma plena interação com os ambientes florestados. Dentro deste contexto, seria adequado sugerir a possibilidade de que as sociedades de caçadores coletores tenham experimentado estratégias de manejo e manipulação de espécies vegetais que, mesmo sem assumir o caráter de uma verdadeira horticultura, podem ter tido um impacto significativo na ampliação dos recursos florestais, no período anterior à chegada dos horticultores de língua Je e Tupi à região. Este padrão já foi sugerido para outra região de Mata Atlântica (De Blasis 1989), podendo mesmo se encontrar na base do processo adaptativo destes grupos aos ambientes densamente florestados da escarpa atlântica do Brasil Meridional.

A cronologia de 1260 anos AP obtida para a região em estudo, encaixa-se também dentro do horizonte de ocupação humana da Tradição Guarani na região, entre 745 e 190 anos AP, de acordo com Ribeiro (1974). Segundo Noelli (1999/2000) a adaptação dos Guarani ao ambiente é autônoma em relação às ofertas de recursos, pois tinham a capacidade de transportar e inserir um conjunto básico com suas plantas úteis na maioria das regiões que conquistaram.

O desenvolvimento das roças Guarani possui características semelhantes às da vegetação sucessional. $\mathrm{O}$ cultivo de vegetais baseava-se no princípio de consorciamento de diferentes espécies, resultando na competição diferencial dos nutrientes por metro quadrado, criando resistência à disseminação de pragas e a diminuição dos impactos da erosão. A área de uma roça era utilizada por vários anos, na medida em que nela, além dos cultígenos de ciclo fenológico, eram introduzidas da mesma forma árvores frutíferas e plantas medicinais ou fornecedoras de matérias primas. Portanto, a evolução e distinção funcional das roças se alteravam de acordo com a sucessão secundária. Quando o número de plantas cultivadas diminuía, novas roças eram abertas em outros pontos, passando as antigas a corresponder a locais onde predominam atividades de coleta (Noelli 1993).

Dentro do espaço do tekohá (espaço no qual se reproduzem as relações econômicas, sociais e político-religiosas essenciais a vida Guarani) haveria florestas primárias, não manejadas, e áreas de florestas secundárias, antropogênicas, cujo manejo poderia iniciar dentro da roça, com a preservação de árvores úteis durante a derrubada ou com o transplante de espécies da floresta primária e secundária para os locais de cultivo. Com esta contínua atividade, diversas áreas de cultivo em torno do raio de ação da aldeia eram criadas para minimizar a procura de plantas úteis e maximizar a oferta de alimentos durante todo o ano. Esta estratégia permitia a substituição da agricultura de plantas anuais por um espaço de plantas perenes, a serem utilizadas até que os processos de sucessão secundária fechassem as clareiras abertas na mata. A formação de pomares, hortas medicinais e o cultivo de plantas manufatureiras também eram desenvolvidas em outros lugares além da roça, podendo situar-se junto às casas, no perímetro da aldeia, nas trilhas que ligam aldeias e roças entre si e em clareiras naturais ou artificiais associadas à derrubada de árvores para a coleta de madeira e mel. Os Guarani também criavam e ampliavam comunidades de uma espécie predominante, como a erva do mate (Ilex) e palmitais (Euterpe), entre outras (Noelli 1993, 1999/2000; Dias 2009). Nas ecozonas 1,2 e 3 da Figura 2 (1260 a $~ 900 \mathrm{AP}$ ), observa-se a presença do Ilex (erva mate) que é uma planta natural da região, sugerindo que a presença desta planta no diagrama possa ser motivada pelo manejo agroflorestal

Os resultados palinológicos aqui apresentados indicam que a área de estudo durante as ocupações dos caçadores coletores e dos horticultores da Tradições Guarani e Taquara era constituída de ambiente aberto com vegetação diversificada (floresta e/ou campo), 
e clima oscilando de úmido a mais seco e bem estacional (chuva em um período e seca em outro). As altas concentrações de partículas de carvão da ecozona $2 i(1000$ a 900 anos AP - Fig. 3) foram muito provavelmente motivadas pela abertura de clareiras para a implantação de roças. O mesmo episódio ocorre na ecozona $4(\sim 600$ anos AP - Fig. 3). A ecozona 2 (vide Fig. 3) apresenta um aumento de áreas florestadas, podendo ter sido explorada através de atividades intensivas para obtenção de recursos (vegetais/ animais), concentradas em um determinado período do ano, garantindo o abastecimento anual através de técnicas de preservação de alimentos. Isso está de acordo com os dados paleoambientais apresentados por Lorscheitter (2003) e Grala \& Lorscheitter (2007) para a região de Serra Velha (RS), que indicam para o período entre 6000 anos AP ao presente expansão da Floresta Atlântica e aumento de umidade com temperaturas mais altas, e atual retirada da Floresta por ação antrópica.

Extrapolando os resultados paleoclimáticos/ paleoambientais da área em estudo para um horizonte cronológico de $~ 3000$ até 190 anos
$\mathrm{AP}$, podemos sugerir que o clima registrado na região do Vale do Rio Caí, permaneceu praticamente estável durante o período de tempo de ocupações da área pelas populações caçadoras coletoras e horticultoras, sugerindo que os sítios arqueológicos parecem ser bons marcadores paleoambientais no que se refere às condições de umidade. De modo geral houve períodos de umidade e clima estacional, contribuindo para a fixação destas populações e favorecendo o abastecimento anual de recursos vegetais e animais variado, correspondendo bem ao perfil das ocupações arqueológicas na região do vale do Rio Caí.

\section{Agradecimentos}

Este trabalho foi desenvolvido no quadro da pesquisa de Pós-Doutoramento do primeiro autor. Os autores agradecem ao MAE/USP pelo apoio institucional. Ao Dr. Paulo Alves de Souza, coordenador do Laboratório de Palinologia do Instituto de Geociências da UFRGS. À Dra. Luciane Coelho pela confecção dos diagramas palinológicos e Denise Dal Pino pelas ilustrações.

BISSA, W.M.; DIAS, A.S.; CATHARINO, E.L.M. Paleoclimatic reconstitution of River Caí valley, northeastern Rio Grande do Sul, with emphasis on human occupation. Revista do Museu de Arqueologia e Etnologia, São Paulo, 19: 143-154, 2009.

Abstract: Palynological analysis of a core from Caí River Valley, northeastern Rio Grande do Sul (Brazil) has shown the record of environmental changes. Samples were treated with HCL, KOH, HF and acetolysis. For each sample a minimum of 300 grains of pollen was counted. The results show at around 1,260 years BP the region occupied by grassland under a dry climate, with a later increase in forest areas at around 1,000 to 600 years BP, when fires occurred, probably originating from human activities. From 600 years BP to the present humidity and temperature increased, and climate became similar to today. Paleoenvironmental data suggest that both grassland and forest areas have been exploited by pre-colonial human population.

Keywords: Palynology - Paleoenvironment - Holocene - Pre-colonial human occupation of Caí River valley (RS). 


\section{Referências bibliográficas}

ARAUJO, A.G.; NEVES, W.; PILÓ, L.

2005 Holocene dryness and human occupation in South América: understanding the "Archaic Gap". Quaternary Research, 64: 298-307.

BAUERMANN, S.

2003 Análises palinológicas e evolução paleovegetacional e paleoambiente das turfeiras de Barrocadas e Águas Claras, Planície Costeira do Rio Grande do Sul, Brasil. Tese de Doutorado. Universidade Federal do Rio Grande do Sul, Porto Alegre.

BEHLING, $\mathrm{H}$.

1997 Late Quaternary vegetational, climate and fire history from the tropical mountain region of Morro de Itapeva, SE Brazil. Palaeogeography, Palaeoclimatology, Palaeoecology, 129: 407-422.

2002 South and southeast Brazilian grasslands during late Quaternary times: a synthesis. Palaeogeography, Palaeoclimatology, Palaeoecology, 177: 19-27.

BEHLING, H.; LICHTE, M.

1997 Evidence of dry and cold climatic conditions at glacial times in tropical southeastern Brazil. Quaternary Research, 48: 348-358.

BEHLING, H.; NEGRELLE, R.

2001 Tropical rain forest climate dynamics of the Atlantic lowland, southern Brazil, during the late Quaternary. Quaternary Research, 56: 383-389.

BEHLING, H.; BAUERMANN, S.; NEVES, P.C.

2001 Holocene environmental changes in the São Francisco de Paula region, Southern Brazil. Journal of South American Earth Sciences, 14 (6): 631-639.

BEHLING, H.; PILLAR, V.; ORLÓCI, L.; BAUERMANN, S.

2004 Late Quaternary Araucaria forest, grassland (campos), fire and climate dynamics, studied by high-resolution pollen, charcoal and multivariate analysis of Cambará do Sul core in southern Brazil. Palaeogeography, Palaeoclimatology, Palaeoecology, 203 (3-4): 277-297.

DE BLASIS, P.A.D.

1989 A ocupação Pré-Colonial do Vale do Ribeira de Iguape, São Paulo: os sítios líticos do Médio Curso. Dissertação de Mestrado, FFLCH/USP.
DIAS, A.S.

1994 Repensando a Tradição Umbu através de um Estudo de Caso. Dissertação de Mestrado, Programa de Pós-graduação em História, Pontifícia Universidade Católica do Rio Grande do Sul.

2003 Sistemas de Assentamento e Estilo Tecnológico: Uma Proposta Interpretativa para a Ocupação Pré-colonial do Alto Vale do Rio dos Sinos, Rio Grande do Sul. Tese de Doutorado, Programa de Pós-graduação em Arqueologia, Museu de Arqueologia e Etnologia da Universidade de São Paulo.

2004 Sistema de assentamento de caçadores coletores no alto vale do rios dos Sinos, Rio Grande do Sul. Revista do CEPA, 28 (39): 7-48.

2009 Um Panorama da Arqueologia PréColonial da Região Sul Brasileira. In: Quaternário do Rio Grande do Sul: Integrando Conhecimentos. Porto Alegre, Sociedade Brasileira de Paleontologia, 255-271.

DIAS, A.S.; JACOBUS, A.

2001 The antiquity of the peopling of southern Brazil. Current Research in the Pleistocene, 18: 17-19.

DIESEL, S.

2005 Estudo Fitosociológico de la Vegetacion de la Cuenca Hidrografica del Rio Cai, Rio Grande do Sul, Brasil. Tese de Doutoramento, Universidad de Leon, Departamento de Biologia vegetal, 503 pp.

FAEGRI, K.; IVERSEN, P.

1989 A Text-book of modern pollen analysis. New York: John Wiley \& Sons, 168 pp.

FEPAM/GTZ,

1997 Levantamento dos principais usos do solo e da água na Bacia Hidrográfica do Rio Caí. Vol. I.

GRALA, M.; LORSCHEIDER, M.L.

2001 Paleoambientes em Serra Velha, RS, Brasil, durante o Holoceno. Boletim de Resumos do VIII Congresso da ABEQUA: 393-394.

2007 Plant succession in a forest on lower Northeast slope of Serra Geral, Rio Grande do Sul, and Holocene palaeoenvironments, Southern Brazil. Acta Bot. Bras., 21 (1): 1-10.

GREHS, S.

1976 Mapeamento geológico preliminar de Santa Cruz do Sul visando obter 
informações básicas ao planejamento integrado. Acta Geológica Leopoldense Estudos Tecnológicos, 1:121-175.

GRIMM, E.C.

1987 CONISS: a Fortran 77 program for stratigraphically constrained cluster analysis by the method of the incremental sum of squares. Computer and Geosciences, 13: 13-35.

IBGE

1986 Levantamento de recursos naturais: geologia, geomorfologia, pedologia, vegetação e uso potencial da terra (V. 33, folha SH 22, Porto Alegre e parte das folhas SH 21, Uruguaiana, e SI 22, Lagoa Mirim). Rio de Janeiro, Fundação Instituto Brasileiro de Geografia e Estatística.

LEDRU, M.P.; BRAGA, P.I.S.; SOUBIÈS, F.; FOURNIER, M.; MARTIN, L.; SUGUIO, K.; TURCQ, B.

1996 The last 50.000 years in the Neotropics (Southern Brazil): evolution of vegetation and climate. Palaeogeography, Palaeoclimatology, Palaeoecology, 123: 239-257.

LEDRU, M.P.; SALGADO-LABOURIAU, M.L.; LORSCHEITTER, M.L.

1998 Vegetation dynamics in southern and central Brazil during the last $10.000 \mathrm{yr}$ BP. Review of Paleobotany and Palynology, 99 (2): 131-142.

LORSCHEITTER, M.L.

2003 Contribution to the Holocene history of Atlantic rain forest in the Rio Grande do Sul state, southern Brazil. Revista del Museo Argentino de Ciencias Naturales 5 (2):261-271.

NOELLI, F.S.

1993 Sem Tekhoa Não Há Tekó (Em Busca de um Modelo Etnoarqueológico da Aldeia e da Subsistência Guarani e sua Aplicação a uma Área de Domínio no Delta do Rio Jacuí, Rio Grande do Sul). Dissertação de Mestrado. Porto Alegre, PUCRS.

1999/2000 A ocupação humana na região sul do Brasil: arqueologia, debates e perspectivas - 1872/2000. Revista USP, 44 (2): 218-269.

RAMBO, B.

1994 A fisionomia do Rio Grande do Sul. São Leopoldo, Editora Unisinos.
RIBEIRO, P.A.M.

1972 Sítio RS-C-14: Bom Jardim Velho (abrigo sob rocha). Iheringia-Antropologia, 2: 15-57.

1974 Primeiras datações pelo método do C-14 para o Vale do Rio Caí, RS. Revista do CEPA, 1: 16-22.

RIBEIRO, P.A.M.; KLANT, S.; BUCHAIN, J.; RIBEIRO, C.

1989 Levantamentos arqueológicos na encosta do planalto entre o vale dos rios Taquari e Caí, RS, Brasil. Revista do CEPA, 16 (19): 49-103.

RIBEIRO, P.A.M.; RIBEIRO, C.

1999 Escavações arqueológicas no sítio RS-TQ58, Montenegro, RS, Brasil. Documentos da FURG, 10: 1-86.

SALGADO-LABOURIAU, M.L.

2001 Reconstruindo as comunidades vegetais e o clima no passado. Revista Humanidades, 48: 24-40.

SCHMITZ, P.I.

1985 Estratégias usadas no estudo dos caçadores-coletores do sul do Brasil. Pesquisas-Antropologia, 40: 75-97.

SEPLAN/IBGE.

1986 Porto Alegre e parte das folhas SH21. Uruguaiana e SH 22 Lagoa Mirim: geologia, geomorfologia, pedologia, vegetação, uso potencial da terra. Fundação Brasileira de Geografia e Estatística. Rio de Janeiro, IBGE, 796pp, 6 mapas.

STEVAUX, J.

2000 Climatic events during the late Pleistocene and Holocene in the upper Paraná river: correlation with NE Argentina and south-central Brazil. Quaternary International, 72: 73-85.

STOCKMARR, J.

1971 Tablets with spores used in absolute pollen analysis. Pollen et Spores, 13: 615-621.

YBERT, J.P.; SALGADO-LABOURIAU, M.L.; BARTH, O.M.; LORSCHEITTER, M.L.; BARROS, M.A.; CHAVES, S.A.M.; LUZ, C.F.P.; RIBEIRO, M.; SCHEEL, R.; VICENTINI, K.F.

1992 Sugestões para Padronização da Metodologia Empregada em Estudos Palinológicos do Quaternário. Revista do Instituto Geológico, 13 (2): 47-49. 